\title{
Contribuições das informações obtidas a partir da Análise Multidimensional de Custos - 0 caso de uma Distribuidora de Alimentos
}

\section{Andesom Nunes de Sousa \\ Graduação em Ciências Contábeis pelo Centro Universitário Estácio do}

Ceará

Rua Ina Brito, 1031 B. Pq Presidente Vargas. Fortaleza/CE, CEP: 60765-645

E-mail: andesomndesousa@gmail.com

Rosângela Venâncio Nunes

Mestrado em Logística e Pesquisa Operacional pela Universidade Federal do

Ceará - UFC

Professora do Centro Universitário Estácio do Ceará

Rua Sebastião de Abreu, ํo 177, apto107C. Maraponga, Fortaleza/CE. CEP:

60710-830

E-mail: angelnuness@gmail.com

Charles Washington Costa de Assis Especialização em Especialização em Auditoria pela Universidade Federal do Ceará - UFC

Professor do Centro Universitário Estácio do Ceará Rua Sebastião de Abreu, № 177, apto 107C. Maraponga. Fortaleza/CE. CEP: 60710-830

E-mail: charles-cont@gmail.com

Rita de Cassia Fonseca Doutorado em andamento em Tecnologia pela Universidade Tecnológica Federal do Paraná - UTFPR Professora da Universidade Estadual do Centro-Oeste - Unicentro Rua Frei Everaldo, ㄲo 3499. Chopinzinho/PR. CEP: 85560-000 E-mail: ritadecfonseca@gmail.com

Nayana de Almeida Adriano Mestrado em Ciências Contábeis pela Universidade de Brasília - UnB Professora Centro Universitário Estácio do Ceará Rua Gustavo Sampaio 1413, apto 1701. Parquelândia. Fortaleza/CE. CEP: 60455-001

E-mail: nayanaadriano@hotmail.com 
Contribuições das informações obtidas a partir da Análise Multidimensional de Custos - 0 caso de uma Distribuidora de Alimentos

Rosângela Venâncio Nunes, Andesom Nunes de Sousa, Charles Washington Costa de Assis, Rita de Cassia Fonseca, Nayana de Almeida Adriano

\section{RESUMO}

Este trabalho tem como objetivo identificar as contribuições que a análise multidimensional de custos logísticos pode oferecer a uma distribuidora de alimentos para eficiência de gestão. Para isso, foi realizado um estudo de caso em uma distribuidora de alimentos, onde seus custos foram estudados por diferentes objetos de análise (Cliente e Região), obtendo o custo e o lucro direto por cliente e área geográfica de distribuição, o que contribuiu para uma gestão mais eficiente. Foi constatado que as informações geradas pelo sistema gerencial e contábil da organização não são suficientes para se conhecer a rentabilidade de cada cliente/região, porque o mesmo não é capaz de apropriar os custos em cada um. A metodologia utilizada para este trabalho foi, a partir de um estudo de caso, uma pesquisa científica aplicada, pois foi utilizado o conhecimento já sistematizado, como gestão de custos logísticos, gestão e análise multidimensional de custos. Esta pesquisa foi relevante porque pode contribuir com informações não geradas a respeito da rentabilidade de cada cliente, dando subsídio para uma gestão mais eficiente, podendo a distribuidora de alimentos em estudo dar prosseguimento ao uso dos métodos aqui descritos, para um maior planejamento e controle.

Palavras-chave: Análise Multidimensional. Distribuidora de Alimentos. Custos Logísticos.

\section{ABSTRACT}

This work aims to identify the contributions that the multidimensional analysis of logistics costs can provide a food distributor for management efficiency. For this we conducted a case study in a food distributor, where costs were studied by different analytical objects (Customer Area), obtaining cost and direct profit per customer and geographic distribution area, which contributed to a more efficient. It was found that the information generated by the management and accounting system of the organization are not sufficient to meet the profitability of each customer / region, because it is not able to appropriate the costs in each. The methodology used for this work was from a case study, applied scientific research, because we used the knowledge already systematized, as management of logistics costs, management and multi-dimensional analysis costs. This research was relevant because it can contribute information not generated about the profitability of each customer, giving subsidy for more efficient management, and may the distribution of food under consideration to continue the use of the methods described herein, for further planning and control.

Keywords: Multidimensional analysis. Distributor Food. Logistical costs. 
Contribuições das informações obtidas a partir da Análise Multidimensional de Custos - 0 caso de uma Distribuidora de Alimentos

Rosângela Venâncio Nunes, Andesom Nunes de Sousa, Charles Washington Costa de Assis, Rita de Cassia Fonseca, Nayana de Almeida Adriano

\section{INTRODUÇÃO}

É fato que o mercado está cada vez mais competitivo, e o resultado econômicofinanceiro tem-se reduzido devido à concorrência, obrigando muitas vezes as empresas a reduzirem seu preço de venda, para permanecerem competitivas. Algumas soluções, como fidelizar o cliente, estratégias de venda e redução de custos estão sendo adotadas para aumentar a competitividade.

Silva Junior (2000) trata sobre essa competitividade quando diz que o modo de fazer negócios mudou radicalmente. Antes o consumidor tinha que satisfazer-se com o que o mercado the oferecia e com os preços determinados pelos fornecedores. Hoje, o cliente não aceita pagar mais por uma característica como qualidade, pois é vista como um atributo do produto. A mudança é significativa ao ponto de, em muitos casos, o consumidor ditar as regras. Ele determina os níveis de preço, e o fornecedor tem de se adaptar para atendê-lo.

Com o significativo aumento da competitividade que vem ocorrendo na maioria dos mercados, os custos tornam-se altamente relevantes. As empresas já não podem decidir seu preço de venda apenas pelos custos incorridos, mas levar em consideração o valor de mercado, conforme registra Martins (2003).

É vital entender como os custos se comportam e como utilizá-los para tomar decisões. "Nos últimos vinte anos, mudanças no ambiente de negócios têm afetado profundamente a contabilidade de custos e gestão de custos. [...]. Essas mudanças estão direcionadas pela necessidade de se criar e sustentar uma vantagem competitiva. " (HANSEN e MOWEN, 2000, p. 07).

Hansen e Wowen (2000) acreditam que, para muitas empresas, as informações para manter a competitividade não podem mais surgir de um sistema tradicional de custos.

É fundamental ao gestor entender como os custos se relacionam na atividade da empresa. Com um eficaz controle interno, é possível gerar essas informações, 
Contribuições das informações obtidas a partir da Análise Multidimensional de Custos - 0 caso de uma Distribuidora de Alimentos

Rosângela Venâncio Nunes, Andesom Nunes de Sousa, Charles Washington Costa de Assis, Rita de Cassia Fonseca, Nayana de Almeida Adriano

colaborando assim para o conhecimento da lucratividade como um todo, para a formação de preço e tomada de decisão.

Sistemas de contabilidade gerencial são estruturados para medir e atribuir custos para objetos de custos. Um objeto de custo é qualquer item, como produtos, clientes, departamentos, processos, atividades, e assim por diante, para o qual os custos são medidos e atribuídos. (HANSEN e MOWEN, 2000, p. 245).

Diante dessa realidade, este artigo busca responder à seguinte questão: Como contribuir para uma gestão de custos logísticos mais eficiente em uma distribuidora de alimentos?

Dessa forma, o objetivo geral é apresentar as contribuições da análise multidimensional de custos logísticos para uma gestão mais eficiente em uma distribuidora de alimentos.

Buscando alcançar o objetivo geral, este trabalho tem ainda os seguintes objetivos específicos:

- Conceituar gestão eficiente e a necessidade de informações de custos logísticos para atingi-la;

- Definir análise multidimensional de custos e apresentar suas ferramentas;

- Realizar estudo de caso em uma distribuidora, descobrindo a Lucratividade Direta por Cliente e Região, através de análises multidimensionais de custos logísticos e identificando como esta ferramenta poderá contribuir para a gestão eficiente do negócio.

Dessa forma, a fim de alcançar tais objetivos, serão tomadas as seguintes hipóteses neste instrumento:

- O sistema contábil por si só, sem uma gestão de custos, não é capaz de fornecer informações como a lucratividade de um cliente/região; 
Contribuições das informações obtidas a partir da Análise Multidimensional de Custos - 0 caso de uma Distribuidora de Alimentos

Rosângela Venâncio Nunes, Andesom Nunes de Sousa, Charles Washington Costa de Assis, Rita de

Cassia Fonseca, Nayana de Almeida Adriano

- Sem o conhecimento em gestão de custos, a empresa não pode mensurar sua real lucratividade, assim como a gestão eficiente dará ao gestor informações importantes para tomada de decisão;

- Com a informação da Lucratividade Direta de cada Região, a organização poderá analisar a hipótese de abrir um novo centro de distribuição;

- Com o resultado da Lucratividade Direta por Cliente, o gestor pode decidir em não fornecer mais para um determinado cliente, devido ao elevado custo, assim como criar políticas para clientes rentáveis;

Conhecimento em gestão de custos torna-se essencial para uma vantagem competitiva.

Assim este trabalho se justifica porque visa contribuir com a análise multidimensional de custos logísticos utilizando como ferramenta a Lucratividade Direta por Cliente e por Região. Esta irá proporcionar ao gestor informações como quais clientes e regiões são mais rentáveis, podendo usar de políticas para aumentar as vendas e manter os custos; entre os clientes, saber qual deles teve resultado negativo e mensurar a viabilidade de mantê-lo como cliente ativo, tomando estratégia para aumentar suas vendas e reduzir os custos.

A metodologia utilizada para este trabalho foi, a partir de um estudo de caso, uma pesquisa científica aplicada, pois foi utilizado o conhecimento já sistematizado, como gestão de custos logísticos, gestão eficiente e análise multidimensional de custos.

A pesquisa é explicativa, por ter várias teorias aplicadas ao problema de como identificar os custos logísticos, e descritiva, porque existem variáveis sobre as quais pode-se fundamentar o estudo. Sua qualificação foi qualitativa, porque este tipo de estudo tem como próprio ambiente a fonte de dados, não utilizando ferramentas estatísticas.

Assim esta pesquisa encontra-se estruturada da seguinte maneira: introdução, referencial teórico, metodologia, estudo de caso e considerações finais. 
Contribuições das informações obtidas a partir da Análise Multidimensional de Custos - 0 caso de uma Distribuidora de Alimentos

Rosângela Venâncio Nunes, Andesom Nunes de Sousa, Charles Washington Costa de Assis, Rita de Cassia Fonseca, Nayana de Almeida Adriano

\section{REFERENCIAL TEÓRICO}

O referencial teórico desta pesquisa apresenta o conceito de Gestão Eficiente, Gestão de Custos Logísticos, Análise Multidimensional de Custos Logísticos e suas ferramentas.

\subsection{Gestão Eficiente}

Gestão significa gerir, administrar os recursos, os bens e equiparados, no caso de uma empresa, na obtenção de acumular recursos.

Luccatto (2011) afirma que o principal objetivo de uma empresa é gerar valor e lucro aos seus acionistas, mas isto não é possível sem uma boa gestão. Completa ainda que gestão é ter controle sobre os processos da empresa.

Eficiência é cumprir os objetivos nos prazos determinados utilizando uma menor quantidade de recurso e tempo. Krieses (2009) explica que eficiência trata de fazer certo a coisa e não fazer a coisa certa. Quando se fala em eficiência, está se falando em produtividade, em fazer mais com o mínimo de recursos possíveis.

\subsubsection{Planejamento e Controle como Ferramenta de Gestão}

Dentre os primeiros passos para uma gestão eficiente estão planejamento e controle. A organização das ideias, posicionando de forma detalhada as ações que serão tomadas, com seus devidos prazos, forma de execução e uma definição clara dos objetivos são algumas características de um planejamento.

É notória a relevância do planejamento para qualquer tipo de atividade, tarefa, evento etc., seja de longo ou curto prazo. $O$ ato de planejar deixa em evidência aquilo que se deseja realizar ou alcançar, concorrendo para uma escolha mais acertada na hora de tomar decisões. Sobre essa questão, é interessante observar o seguinte pensamento: "A existência de objetivos e metas previamente identificados é premissa básica para a tomada de qualquer decisão, seja no ambiente de negócios ou em nossa própria vida" (SILVA JÚNIOR, 2000, p. 132). 
Contribuições das informações obtidas a partir da Análise Multidimensional de Custos - 0 caso de uma Distribuidora de Alimentos

Rosângela Venâncio Nunes, Andesom Nunes de Sousa, Charles Washington Costa de Assis, Rita de Cassia Fonseca, Nayana de Almeida Adriano

Faria e Costa (2005) dizem que, para a logística, os custos devem estar voltados às necessidades de planejamento e controle tanto do produto, canal de distribuição, região quanto da rentabilidade por cliente.

Para verificar de forma temporal e estabelecer ações corretivas para a não execução do planejamento, estabelecemos os processos de controle. Com planejamento e controle bem definidos, é possível dar informações aos gestores para tomada de decisão.

A gestão de custos produz informações para usuários internos. Especificamente, a gestão especifica, coleta, mensura, classifica e relata informações que são úteis aos gestores para o custeio (determinar quanto algo custa), planejamento, controle e tomadas de decisão. A gestão de custos requer uma compreensão profunda da estrutura de custos da empresa. (HANSEN E MOWEN, 2000, p. 38).

Hansen e Mowen (2000) afirmam que planejamento é a formulação detalhada de ação para se realizar um fim em particular. Controle são os processos de monitorar a implementação de um plano, e as informações sobre custos que são fornecidas têm um papel de apoio importante para o planejamento, controle e tomada de decisão.

\subsubsection{Gestão do Sistema de Custo}

A implantação de um sistema de custos está entre as primeiras ferramentas para a gestão eficiente. Faria e Costa (2005) referem que a Tecnologia de Informação vem sendo uma importante fonte de melhoria da produtividade e competitividade, visando à minimização dos custos e à otimização dos resultados econômicos.

Sobre o sistema de custos, Ferreira afirma que: 
Contribuições das informações obtidas a partir da Análise Multidimensional de Custos - 0 caso de uma Distribuidora de Alimentos

Rosângela Venâncio Nunes, Andesom Nunes de Sousa, Charles Washington Costa de Assis, Rita de

Cassia Fonseca, Nayana de Almeida Adriano

Assim, para a implantação de um sistema de custos, será necessário observar alguns passos, tais como: 1) formação de equipe e treinamento; 2) estabelecimento dos objetivos; 3) construção da matriz atividades versus áreas funcionais; 4) determinação dos fatores de consumo; 5) cálculo dos custos das atividades; 6) determinação dos indutores de custo; e 7) cálculo dos objetivos. (FERREIRA, 2007, p. 323).

Hansen e Mowen (2000) afirmam que o foco dos sistemas de contabilidade gerencial foi ampliado para possibilitar que os gestores possam melhor atender as necessidades dos clientes e que, para manter uma vantagem competitiva, os gestores precisam enfatizar o tempo, a qualidade e a eficiência.

Enquanto a qualidade e o tempo são importantes, melhorar essas dimensões sem melhorias correspondentes no desempenho financeiro pode ser fútil, se não fatal [...]. Tanto medidas financeiras quanto não-financeiras da eficiência são necessárias. O Custo é uma medida crítica da eficiência. (HANSEN; MOWEN, 2000, p. 35).

Ainda no caso da fábrica de mesas, a título de ilustração, a empresa foi ampliada e produz três tipos de mesa: cada uma utiliza quantidade diferente de matéria prima, assim como mão de obra e outros custos indiretos. A implementação de um sistema de custos irá proporcionar informações mais precisas quanto ao custo de cada mesa. Mão de obra, matéria prima, energia elétrica, manutenção das máquinas, esses são exemplos de custos indiretos que melhor são rateados através de um sistema de custos.

\subsubsection{Gestão Estratégica}

Outro ponto importante para a gestão eficiente é a estratégia da empresa; Horngren et al. (1997) dizem que a estratégia especifica como uma organização combina suas próprias capacidades com as oportunidades existentes no mercado para realizar seus objetivos. 
Contribuições das informações obtidas a partir da Análise Multidimensional de Custos - 0 caso de uma Distribuidora de Alimentos

Rosângela Venâncio Nunes, Andesom Nunes de Sousa, Charles Washington Costa de Assis, Rita de

Cassia Fonseca, Nayana de Almeida Adriano

Um posicionamento estratégico, visando manter-se no mercado em condições de competitividade, ou seja, uma posição de mercado que represente situação favorável ante aos concorrentes, é essencial, cita Wernke (2004).

A logística, por sua vez, faz parte da gestão estratégica da organização, porque traz vantagem competitiva, oferecendo um melhor nível de serviço aos clientes como redução dos Custos Logísticos e melhoria na rentabilidade, segundo Faria e Costa (2005).

Tomando ainda como exemplo a fábrica de mesas, uma decisão estratégica para essa organização é a escolha do público-alvo, por exemplo. Ao escolher um público de padrão $A$, sabe-se que é necessária uma maior qualidade de matéria prima e design, concorrendo assim com outros fabricantes que ofereçam qualidade de produto semelhante. Essa é uma estratégia para ganhar posição no mercado perante seus concorrentes.

\subsection{Gestão de Custos Logísticos}

A logística administra, de forma estratégica, toda a movimentação a partir da aquisição de materiais até a sua chegada ao consumidor.

$\mathrm{Na}$ base do moderno conceito de logística integrada, está o entendimento de que a Logística deve ser vista como um instrumento de marketing, uma ferramenta gerencial capaz de agregar valor por meio dos serviços prestados. (FLEURY et al., 2000, p. 31).

Faria e Costa (2005) mencionam Christopher (1997), que conceitua logística como o processo de gerenciar, estrategicamente, a aquisição, movimentação e armazenagem de materiais, peças e produtos acabados por meio da organização e seus canais de marketing, de modo a poder maximizar as lucratividades, presentes e futuras através do atendimento dos pedidos a baixo custo.

O objetivo da logística é tornar disponível produtos e serviços no local onde são necessários, no momento em que são desejados". (BOWERSOX e CLOSS, 2010, p. 19). 
Contribuições das informações obtidas a partir da Análise Multidimensional de Custos - 0 caso de uma Distribuidora de Alimentos

Rosângela Venâncio Nunes, Andesom Nunes de Sousa, Charles Washington Costa de Assis, Rita de Cassia Fonseca, Nayana de Almeida Adriano

Bowersox e Closs (2010) ainda afirmam que a responsabilidade operacional da logística está diretamente relacionada à disponibilidade de matérias primas, produtos semiacabados e estoques de produtos acabados, no local onde são requisitados, ao menor custo possível.

O objetivo básico da Logística, segundo Novaes (2001), citado por Duarte (2012), é tratar as atividades Logísticas como um sistema, de forma a garantir sua eficiência, reduzindo custos e tempos de entrega. Duarte (2012) continua dizendo que o nível de serviço, que é o indicador se a Logística da empresa cumpre ou não com os compromissos assumidos, é o conceito de entregar o que o cliente quer, na hora que ele precisa.

Faria e Costa (2005) citam a definição dos "cinco certos" de um sistema logístico definido por Plowman, in Lambert et al. (1998, p. 10), que afirma ser o objetivo da logística a forma de prover ao cliente os níveis de serviços por ele requeridos, com a entrega do produto certo, no lugar certo, no momento certo, nas condições certas e pelo custo certo.

Bowersox e Closs (2010) tratam também sobre competências logísticas. Estas decorrem de uma avaliação relativa da capacitação de uma empresa para fornecer ao cliente um serviço competitivamente superior ao menor custo total possível. Busca-se então executar as atividades com o máximo de excelência, desde o recebimento de pedidos até a condução do caminhão. Esta competência é alcançada pela coordenação de: (1) um projeto de rede; (2) informações; (3) transporte; (4) estoque; e (5) armazenagem, manuseio de materiais e embalagem.

As informações contábeis e, mais precisamente, a gestão de Custos são extremamente relevantes para o processo decisório em uma empresa, afirma Faria e Costa (2005). As informações contábeis são fundamentais para essa gestão, segundo Garrison e Noreen (1994), citado por Faria e Costa (2005). Eles ainda ressaltam que o sistema contábil é bastante criticado na literatura logística por não conseguirem suprir as necessidades dos gestores logísticos, pois as informações geradas, muitas vezes, não condizem com a realidade da empresa. 
Contribuições das informações obtidas a partir da Análise Multidimensional de Custos - 0 caso de uma Distribuidora de Alimentos

Rosângela Venâncio Nunes, Andesom Nunes de Sousa, Charles Washington Costa de Assis, Rita de Cassia Fonseca, Nayana de Almeida Adriano

O ambiente econômico atual tem criado grande competitividade, exigindo das empresas um menor preço em seu produto e diminuindo o resultado econômicofinanceiro de muitas organizações. Consequentemente, deu-se início a práticas inovadoras e relevantes para a gestão de custos, ratificam Hansen e Mowen (2000).

Em relação à necessidade de conhecer todos os custos inerentes ao processo logístico, Faria e Costa comentam:

Diante de um contexto de intensa competitividade, na maioria dos seguimentos da economia, a gestão dos Custos Logísticos tem como objetivo principal estabelecer políticas que possibilitem às empresas, simultaneamente, uma redução nos custos e a melhoria do nível de serviço oferecido ao cliente. Para isso, é preciso conhecer quais são os custos inerentes a todo o processo logístico. (FARIA E COSTA, 2005, p. 67).

Os custos logísticos têm uma representação significativa dentro das empresas.

A ABML estima que o custo logístico em uma empresa pode equivaler a $19 \%$ do seu faturamento. Assim é de suma importância para a empresa saber identificar e mensurar esse tipo de custo que pode significar muitas vezes a própria existência da empresa [...] A falta de informação sobre custos é uma das maiores causas para a dificuldade que muitas companhias têm no processo de adoção de uma abordagem integrada para a logística e para o gerenciamento de distribuição. (NOGUEIRA, 2014).

As empresas necessitam de informações precisas sobre custos em todos os aspectos da empresa, do projeto e desenvolvimento à produção, marketing e entrega e serviços aos clientes pós-compra. O acúmulo de informações de custos detalhadas e precisas ajuda as empresas a determinar a rentabilidade da empresa como um todo, assim como o custo e a rentabilidade de cada viagem do caminhão, afirmam Hansen e Mowen (2000). 
Contribuições das informações obtidas a partir da Análise Multidimensional de Custos - 0 caso de uma Distribuidora de Alimentos

Rosângela Venâncio Nunes, Andesom Nunes de Sousa, Charles Washington Costa de Assis, Rita de

Cassia Fonseca, Nayana de Almeida Adriano

Alguns autores mencionam Gestão de Custos Logísticos como atividade de novas estratégias.

A Gestão de Custos Logísticos é a atividade de utilização ou desenvolvimento de novas estratégias para gerenciamento dos respectivos custos. Tem por objetivo monitorar os custos operacionais dos serviços logísticos, por meio de indicadores, visando a acompanhar resultados, tendências e oportunidades, bem como desenvolver estudos de impacto logístico e respectivo custeio, de maneira a dar suporte ao processo de tomada de decisão em seus diversos níveis: estratégico, tático e operacional. (FARIA E COSTA, 2005, p. 184).

É possível notar, com a explanação desses autores, a grande relevância da gestão logística no mercado: a gestão, já conceituada como a forma de administrar os recursos, e a logística, como gerenciamento da aquisição, movimentação e venda dos bens e serviços.

\subsection{Análise Multidimensional de Custos Logísticos e suas Ferramentas}

Esta análise tem por objetivo principal determinar a rentabilidade da organização, tomando como objeto de análise não apenas o produto, pois este não é o único gerador de despesas/custos e receitas, mas também os clientes, itens, pedidos e região.

Michaelis (2005), citado por Faria e Costa (2005), salientam que Multidimensional está associado a um espaço de mais de três dimensões. Trata-se da análise de Rentabilidade como multidimensional, pois pode ser realizada para diferentes objetos, tais como: produtos, regiões, clientes, canal de distribuição etc.

Um objeto de custo é qualquer item, como produtos, clientes, departamentos, processos, atividades e assim por diante, para o qual os custos são medidos e atribuídos. (HANSEN E MOWEN, 2000, p. 61).

Faria e Costa (2005) afirmam que, por meio de análises multidimensionais, o gestor é capaz de determinar padrões de rentabilidade e descobrir oportunidades e ameaças. Ressalta, ainda, que é possível otimizar o resultado econômico da empresa. 
Contribuições das informações obtidas a partir da Análise Multidimensional de Custos - 0 caso de uma Distribuidora de Alimentos

Rosângela Venâncio Nunes, Andesom Nunes de Sousa, Charles Washington Costa de Assis, Rita de

Cassia Fonseca, Nayana de Almeida Adriano

Reeve (1998), citado por Faria e Costa, sugere uma estrutura conceitual para que sejam analisados os resultados por item, pedidos, clientes e regiões.

A este respeito, ratificam os autores:

Os métodos de custeio estão relacionados à forma de atribuir os custos aos produtos ou outros objetos, tais como: Clientes, regiões, canais de distribuições etc. [...] Existem vários métodos para a contabilização dos custos e alguns amplamente utilizados, tais como: Custeio por Absorção, custeio variável, custeio direto e, atualmente, bastante disseminado no meio empresarial, e principalmente na Logística, Custeio Baseado em Atividade - ABC. (FARIA e COSTA, 2005, p. 237).

Essas autoras ainda citam Lambert et al. (1998), dizendo que, com relatórios de rentabilidade por diversos seguimentos, os gestores podem determinar com mais precisão as opções estratégicas, como quais linhas de produtos devem ou não ser abandonadas; quais os preços que devem ser aumentados; e eliminar linhas de produtos não lucrativos, entre outras questões.

A ferramenta de custeio Análise Direta por Cliente/Região será apresentada no próximo tópico como estrutura da análise multidimensional de custos para ser aplicada no estudo de caso, dando assim as contribuições esperadas.

\subsubsection{Lucratividade Direta por Cliente/Região}

O custo de cada cliente será bastante variado, porque cada cliente vai exigir recursos diferentes para serem atendidos; por diversos motivos, os custos irão variar de um cliente para o outro. Em uma distribuidora, o custo para entregar um produto em outra cidade é maior do que se a entrega fosse próxima. Os custos variáveis como mão de obra, manutenção do veículo e combustível irão aumentar.

Horngren et al. (2004) mencionam que a Análise da Lucratividade por Cliente é o relato e a análise das receitas obtidas dos clientes e dos custos incorridos para alcançá-las. Eles afirmam também que uma análise das diferenças dos clientes em 
Contribuições das informações obtidas a partir da Análise Multidimensional de Custos - 0 caso de uma Distribuidora de Alimentos

Rosângela Venâncio Nunes, Andesom Nunes de Sousa, Charles Washington Costa de Assis, Rita de Cassia Fonseca, Nayana de Almeida Adriano

receitas e custos proporciona a explicação das diferenças nos lucros operacionais obtidos de diferentes clientes.

O resultado da análise de lucratividade por cliente proporciona ao gestor subsídio para estratégias individuais para cada cliente, aumentando assim o resultado de cada um.

Para Christopher (1997), citado por Faria e Costa (2005), o princípio básico da rentabilidade por cliente é alocar todos os custos específicos em contas individuais, ou seja, quais os custos exclusivos que seriam evitados se não houvesse negócio com um cliente específico. O autor enfatiza os custos da Logística de Distribuição e apresenta uma lista de custos que devem ser incluídos na rentabilidade de cada cliente.

\begin{tabular}{|l|l|}
\hline & - Custo de processamento de pedidos; \\
& - Embalagem; \\
(Somente custos identificáveis) & - Custo de Manutenção de Estoque Exclusivo; \\
& - Espaço exclusivo do Armazém; \\
& - Custo de Manuseio de Materiais; \\
& - Custo de transporte; \\
& - Custo de Manutenção/Comunicação (TI)
\end{tabular}

Quadro 1: Itens da análise de rentabilidade por Cliente Fonte: Adaptado de Faria e Costa (2005, p. 344), que citou Christopher (1997, p. 72).

Um custo de difícil associação com o cliente é o de Armazenagem, para identificar o espaço exclusivo no armazém, se não houver um procedimento específico de segregação dos estoques por cliente, completam Faria e Costa (2005).

Lucratividade Direta por região se utiliza do mesmo método da Lucratividade Direta por Cliente e pode ser utilizada para avaliar a rentabilidade de cada uma, dando suporte para tomada de decisão, como intensificar ou não as vendas em uma região, fazer uma maior divulgação, lançar promoções etc. 
Contribuições das informações obtidas a partir da Análise Multidimensional de Custos - 0 caso de uma Distribuidora de Alimentos

Rosângela Venâncio Nunes, Andesom Nunes de Sousa, Charles Washington Costa de Assis, Rita de Cassia Fonseca, Nayana de Almeida Adriano

\section{METODOLOGIA}

Este trabalho trata-se de uma pesquisa cientifica porque procurou um conjunto de ações e propostas para um determinado problema que, no caso, é como contribuir para uma gestão de custos eficiente de uma distribuidora de alimentos.

\subsection{Objeto de Estudo}

Quanto à classificação, a pesquisa é científica aplicada. Almeida (2011) refere que pesquisa científica aplicada, normalmente, faz uso dos conhecimentos que já foram sistematizados, como análise multidimensional de custos, lucratividade direta por Cliente e Região. O objetivo foi de contribuir para uma maior eficiência, visando também à redução dos custos e à otimização de resultados organizacionais. Para isso, foi selecionada a opção de estudo de caso, visando observar e compreender em detalhes a realidade da empresa.

Quanto aos seus objetivos, o tipo de pesquisa foi categorizado como explicativa e descritiva: a primeira hipótese porque, como diz Almeida (2011), teve como foco a identificação de fatores (custos) que contribuem para determinados resultados, a partir de objetos específicos, como clientes e área geográfica de atuação da distribuidora em questão. Sampieri et al. (2006) afirmam que estudos explicativos podem nos revelar que existe uma ou várias teorias que se aplicam ao nosso problema de pesquisa.

Descritiva porque, como dizem Sampieri, et al. (2006), nesta pesquisa são detectadas e descritas certas variáveis sobre as quais podemos fundamentar o estudo, teorias já escritas por: Faria e Costa (2005); Bowersox, Donald e Closs (2010); Horngren, Foster e Datar (2004); Hansen e Mowen (2000), além de outros.

No que diz respeito à abordagem, é classificada como qualitativa, considerando que esse tipo de estudo tem o ambiente natural como fonte de dados, não utilizando ferramentas estatísticas para tratamento dos mesmos e, sim, o enfoque analítico, atribuindo maior importância aos significados dados pelas pessoas aos fatos, como trata Almeida (2011). 
Contribuições das informações obtidas a partir da Análise Multidimensional de Custos - 0 caso de uma Distribuidora de Alimentos

Rosângela Venâncio Nunes, Andesom Nunes de Sousa, Charles Washington Costa de Assis, Rita de Cassia Fonseca, Nayana de Almeida Adriano

\subsection{Procedimentos de Coleta de Dados}

Os dados da pesquisa foram coletados in loco, mediante o sistema gerencial e sistema contábil; assim puderam ser adquiridos maiores conhecimentos sobre a realidade organizacional e seus problemas no campo da apuração e rateio de custos. Por meio de entrevista com o gerente de logística e, posteriormente, com o gestor, foram obtidas informações sobre o funcionamento logístico da organização. Os dados são usados na análise multidimensional de custos, e as informações estão descritas também no mesmo tópico.

\subsection{Procedimentos de Análise de Dados}

A pesquisa se desenvolveu a partir do levantamento de custos sob dois ângulos: Clientes e Área geográfica de atuação (região), sendo feitos levantamentos de faturamentos e custos indiretos. A mão de obra, manutenção do veículo, despesa com aluguel de veículo e combustível foram rateados para se chegar ao resultado da Lucratividade Direta por Cliente e por Praça.

A partir dessas informações, torna-se possível tomar medidas preventivas e corretivas que proporcionem redução de custos e, consequentemente, aumento de lucratividade, ou seja, otimização de resultados com a mesma quantidade de recursos.

\section{ESTUDO DE CASO}

O estudo de caso foi elaborado primeiramente por meio de uma pesquisa bibliográfica, embasando todo o trabalho por meio de fundamentação teórica, além de uma coleta de dados em uma empresa distribuidora de Alimentos que será objeto do estudo de caso.

Tendo como objetivo geral identificar as contribuições da análise multidimensional de custos logísticos na empresa Alfa, como será chamada de forma ilustrativa, foram usados como objeto de análise os clientes e as regiões de distribuição (praça) da empresa. O gestor nos forneceu dados necessários para que as análises 
Contribuições das informações obtidas a partir da Análise Multidimensional de Custos - 0 caso de uma Distribuidora de Alimentos

Rosângela Venâncio Nunes, Andesom Nunes de Sousa, Charles Washington Costa de Assis, Rita de

Cassia Fonseca, Nayana de Almeida Adriano

fossem feitas, como peso da mercadoria distribuída a cada cliente, valor do faturamento e Lucro Bruto. A contabilidade ainda nos forneceu dados de alguns custos indiretos, como despesas com veículos, mão de obra e combustível.

As ferramentas apresentadas no referencial teórico, Lucratividade Direta por Cliente/Praça e a análise multidimensional de custos foram usadas para desenvolver a pesquisa.

Faria e Costa (2005) afirmam que muitos autores da literatura logística criticam os sistemas contábeis por não conseguirem suprir as necessidades dos gestores logísticos. Diante disso, este trabalho estudou o processo logístico da empresa para contribuir com informações relevantes.

\subsection{O Ambiente em estudo}

Considerada de médio porte, a empresa, aqui denominada Alfa, atende quase todo o estado do Ceará. Com mais de 4000 clientes em 2013, tem como uma de suas missões ser uma empresa reconhecida pela dedicação, honestidade e integralidade. Possui pouco mais de 200 funcionários, um caminhão e aluguel de outros para a distribuição das mercadorias. Suas atividades deram início em 2003, e seu crescimento tem sido progressivo.

A empresa possui um mix de produtos de marca própria do setor de cereais. Estes são adquiridos do próprio agricultor. Na maioria das vezes, a preparação e embalagem dos produtos são terceirizadas e entregues no centro de distribuição; em outras, este processo é feito no próprio centro.

A empresa procura utilizar, ao máximo, competências logísticas para obter vantagens competitivas, estratégia esta citada no referencial teórico.

Suas operações funcionam da seguinte forma: a mercadoria adquirida chega pelo portão de descarrego e é levada para ser endereçada; após a inclusão no sistema, o mesmo já direciona para o local predeterminado. Quando a mercadoria é vendida pelo representante, o centro de distribuição recebe a informação e a encaminha para o 
Contribuições das informações obtidas a partir da Análise Multidimensional de Custos - 0 caso de uma Distribuidora de Alimentos

Rosângela Venâncio Nunes, Andesom Nunes de Sousa, Charles Washington Costa de Assis, Rita de

Cassia Fonseca, Nayana de Almeida Adriano

faturista. Para uma maior produtividade, o gerente de logística agenda a entrega por seguimento de região.

A organização possui um sistema gerencial que fornece informações de grande utilidade. Este é alimentado sempre que ocorre um fato entre a compra das mercadorias e a venda. Uma vez bem alimentado, o sistema vai fornecer, por exemplo, os seguintes dados: qual o estoque de cada mercadoria, preço de compra e preço de venda; margem de lucro; quantidade vendida para cada cliente; peso da mercadoria transportada, além de muitas outras informações.

Mesmo com tantas informações, esse sistema não é capaz de reconhecer a Lucratividade Direta dos clientes e regiões, nem mesmo o sistema contábil, que não apropria todos os custos incorridos pelo cliente ao cliente. É este tipo de contribuição que este estudo vem fornecer. Nos próximos tópicos, serão desenvolvidas as análises da lucratividade direta por cliente e por região (praça), serão apropriados ao objeto de análise todos os custos que são incorridos para aquela venda.

\subsection{Lucratividade Direta por Cliente}

Como já dito no referencial teórico, esta análise tem o objetivo de buscar a rentabilidade dos principais clientes.

Faria e Costa (2005) afirmam que os métodos de custeio estão relacionados à forma de atribuir os custos aos produtos ou a outros objetos. Nesse método de custeio, foram apropriados, primeiramente, os custos às atividades e, posteriormente, ao cliente, que é o objeto de análise. As atividades são duas: mão de obra (carrego, descarrego e faturamento) e transporte (despesas com veículos), posteriormente somados as atividades com as mercadorias.

Por meio de um sistema gerencial, a empresa forneceu os dados de 4.296 clientes, em que foi feita uma amostragem com 20 destes, demonstrados na Tabela 1 , apresentando os seguintes dados (os clientes estão em ordem de faturamento):

-Peso da mercadoria, que influenciará tanto no custo da mão de obra quanto no transporte, como veremos mais adiante; 
Contribuições das informações obtidas a partir da Análise Multidimensional de Custos - 0 caso de uma Distribuidora de Alimentos

Rosângela Venâncio Nunes, Andesom Nunes de Sousa, Charles Washington Costa de Assis, Rita de Cassia Fonseca, Nayana de Almeida Adriano

- Valor do faturamento filtrado pelo cliente e o lucro bruto (valor de venda - valor de compra), que é fundamental para calcular.

Vale ressaltar que foram escolhidos, entre os clientes da amostra, alguns que já estão com prejuízo em seus resultados. A escolha foi feita para melhor demonstrar como um único cliente pode diminuir o resultado da empresa.

$\mathrm{Na}$ análise da Lucratividade Direta por Cliente, será agregada, além do valor da mercadoria, a mão de obra, a comissão dos representantes e os gastos com o transporte da mercadoria. Dessa forma, os próximos tópicos estarão divididos em: Mão de obra e Transporte. O gasto com transporte agrega a manutenção com veículo, o aluguel de veículos e o combustível.

Tabela 1: Amostra de Clientes

\begin{tabular}{|c|c|c|c|c|}
\hline & Cliente & Peso Kg & Valor de Venda & \% Lucro \\
\hline 1 & Cliente A & 950.189 & $3.039 .103,30$ & $9,80 \%$ \\
\hline 2 & Cliente B & 723.396 & $1.970 .128,13$ & $7,65 \%$ \\
\hline 3 & Cliente C & 370.372 & $1.515 .469,82$ & $11,21 \%$ \\
\hline 4 & Cliente D & 192.013 & $1.174 .038,36$ & $12,39 \%$ \\
\hline 5 & Cliente E & 336.911 & $1.107 .421,76$ & $10,48 \%$ \\
\hline 6 & Cliente F & 270.449 & $1.074 .690,12$ & $9,90 \%$ \\
\hline 7 & Cliente G & 367.705 & $1.055 .680,16$ & $10,21 \%$ \\
\hline 8 & Cliente H & 410.505 & $1.013 .670,42$ & $8,79 \%$ \\
\hline 9 & Cliente I & 152.869 & $575.670,18$ & $9,17 \%$ \\
\hline 10 & Cliente J & 95.327 & $244.473,63$ & $8,84 \%$ \\
\hline 11 & Cliente K & 4.410 & $12.056,16$ & $24,31 \%$ \\
\hline 12 & Cliente L & 257 & $5.577,28$ & $32,75 \%$ \\
\hline 13 & Cliente M & 1190 & $4.449,90$ & $27,08 \%$ \\
\hline 14 & Cliente N & 810 & $3.474,82$ & $29,16 \%$ \\
\hline 15 & Cliente O & 701 & $3.146,16$ & $30,89 \%$ \\
\hline 16 & Cliente P & 575 & $3.021,47$ & $33,10 \%$ \\
\hline 17 & Cliente Q & 131 & $1.329,74$ & $-19,52 \%$ \\
\hline 18 & Cliente R & 1020 & $1.320,00$ & $34,34 \%$ \\
\hline 19 & Cliente S & 62 & 723 & $-22,02 \%$ \\
\hline 20 & Cliente T & 135 & 678,21 & $-35,93 \%$ \\
\hline & TOTAL & $\mathbf{3 . 8 7 9 . 0 2 7}$ & $\mathbf{1 2 . 8 0 6 . 1 2 3 , 6 2}$ & \\
\hline
\end{tabular}

Fonte: Dados da Pesquisa (2013). 
Contribuições das informações obtidas a partir da Análise Multidimensional de Custos - 0 caso de uma Distribuidora de Alimentos

Rosângela Venâncio Nunes, Andesom Nunes de Sousa, Charles Washington Costa de Assis, Rita de Cassia Fonseca, Nayana de Almeida Adriano

\subsubsection{Mão de Obra}

A mão de obra que pode ser alocada diretamente ao objeto cliente é composta por 01 (um) faturista que emitirá as notas fiscais no momento da venda, 36 motoristas, 50 ajudantes que carregam e descarregam os caminhões e pela comissão dos representantes comerciais, que é uma média de $1,5 \%$ da venda.

O objeto de rateio mais fidedigno para apropriar a mão de obra aos clientes, com exceção dos representantes comerciais, seria a quantidade de entregas para cada cliente, porque, em cada entrega realizada, a mão de obra é gasta. Como a empresa não tem essa informação disponível, foi usado o peso da mercadoria; entende-se também que, quanto maior o peso, maior a necessidade de mão de obra para carregar e descarregar o caminhão, além do tempo gasto para fazê-lo. O peso dos vinte clientes da amostragem corresponde a $12,80 \%$ do peso total das mercadorias entregues a todos os clientes. Isso quer dizer que, do custo total com pessoal, apenas esse percentual será apropriado aos clientes da amostra.

O custo de mão de obra, em 2013, fica de acordo com as Tabelas 2 e 3:

Tabela 2: Salários e Encargos

\begin{tabular}{|c|c|r|r|r|r|r|r|}
\hline Salário & $\begin{array}{c}\text { Salário 11 } \\
\text { meses }\end{array}$ & Férias & Décimo & $\begin{array}{c}\text { Salário+ } \\
\text { Férias+ } \\
\text { Décimo }\end{array}$ & FGTS 8\% & $\begin{array}{c}\text { INSS } \\
\mathbf{2 2 \%}\end{array}$ & TOTAL \\
\hline 724,00 & $7.964,00$ & 965,00 & 724,00 & $9.653,00$ & 772,00 & $2.124,00$ & $12.549,00$ \\
\hline
\end{tabular}

Fonte: Dados da Pesquisa (2013). 
Contribuições das informações obtidas a partir da Análise Multidimensional de Custos - 0 caso de uma Distribuidora de Alimentos Rosângela Venâncio Nunes, Andesom Nunes de Sousa, Charles Washington Costa de Assis, Rita de Cassia Fonseca, Nayana de Almeida Adriano

Tabela 3: Mão-de-Obra direta

\begin{tabular}{|l|c|c|r|}
\hline Função & $\begin{array}{c}\text { Quant. } \\
\text { mão-de- } \\
\text { obra }\end{array}$ & $\begin{array}{c}\text { Custo de } \\
\text { Mão-de- } \\
\text { Obra } \\
\text { Unitária }\end{array}$ & TOTAL \\
\hline Motoristas & 36 & $12.549,00$ & $451.764,00$ \\
\hline Ajudantes & 50 & $12.549,00$ & $27.450,00$ \\
\hline Faturista & 1 & $12.549,00$ & $12.549,00$ \\
\hline & $\mathbf{8 7}$ & & $\mathbf{1 . 0 9 1 . 7 6 3 , 0 0}$ \\
\hline
\end{tabular}

Fonte: Dados da Pesquisa (2013).

Sabendo-se que o custo com mão de obra, apresentado na Tabela 3, será rateado pelos clientes da amostra de acordo com o peso da mercadoria e que o peso das mercadorias dos clientes em análise corresponde a $12,80 \%$ do total, o rateio ficará conforme a Tabela 4: 
Contribuições das informações obtidas a partir da Análise Multidimensional de Custos - 0 caso de uma Distribuidora de Alimentos Rosângela Venâncio Nunes, Andesom Nunes de Sousa, Charles Washington Costa de Assis, Rita de Cassia Fonseca, Nayana de Almeida Adriano

Tabela 4: Rateio da mão de obra aos clientes

\begin{tabular}{|c|c|c|c|c|}
\hline & Cliente & Peso Kg & Peso & $\begin{array}{l}\text { Mão-de- } \\
\text { Obra }\end{array}$ \\
\hline 1 & Cliente A & 950.189 & $24,50 \%$ & $34.231,47$ \\
\hline 2 & Cliente B & 723.396 & $18,65 \%$ & $26.061,03$ \\
\hline 3 & Cliente C & 370.372 & $9,55 \%$ & $13.343,01$ \\
\hline 4 & Cliente D & 192.013 & $4,95 \%$ & $6.917,45$ \\
\hline 5 & Cliente $\mathrm{E}$ & 336.911 & $8,69 \%$ & $12.137,54$ \\
\hline 6 & Cliente F & 270.449 & $6,97 \%$ & $9.743,18$ \\
\hline 7 & Cliente $\mathrm{G}$ & 367.705 & $9,48 \%$ & $13.246,92$ \\
\hline 8 & Cliente $\mathrm{H}$ & 410.505 & $10,58 \%$ & $14.788,84$ \\
\hline 9 & Cliente I & 152.869 & $3,94 \%$ & $5.507,25$ \\
\hline 10 & Cliente $\mathrm{J}$ & 95.327 & $2,46 \%$ & $3.434,25$ \\
\hline 11 & Cliente $\mathrm{K}$ & 4.410 & $0,11 \%$ & 158,87 \\
\hline 12 & Cliente L & 257 & $0,01 \%$ & 9,26 \\
\hline 13 & Cliente M & 1.190 & $0,03 \%$ & 42,87 \\
\hline 14 & Cliente $\mathrm{N}$ & 810 & $0,02 \%$ & 29,18 \\
\hline 15 & Cliente $\mathrm{O}$ & 701 & $0,02 \%$ & 25,25 \\
\hline 16 & Cliente P & 575 & $0,02 \%$ & 20,71 \\
\hline 17 & Cliente Q & 131 & $0,00 \%$ & 4,72 \\
\hline 18 & Cliente $\mathrm{R}$ & 1.020 & $0,03 \%$ & 36,75 \\
\hline 19 & Cliente S & 62 & $0,00 \%$ & 2,23 \\
\hline 20 & Cliente $\mathrm{T}$ & 135 & $0,00 \%$ & 4,86 \\
\hline \multicolumn{2}{|c|}{ TOTAL } & 3.879 .027 & $100 \%$ & $139.745,66$ \\
\hline
\end{tabular}

Fonte: Dados da Pesquisa (2013).

\subsubsection{Transporte}

Nos gastos com o transporte, existem alguns custos indiretos que serão rateados aos clientes.

Com a quantidade de pedidos e a distância entre o cliente e o centro de distribuição, tem-se os quilômetros rodados para cada empresa. Cada cliente tem um percentual de quilômetro rodado em relação ao todo. Ao se dividir os gastos com transporte de forma proporcional a este percentual, tem-se os custos com transporte por cliente. 
Contribuições das informações obtidas a partir da Análise Multidimensional de Custos - 0 caso de uma Distribuidora de Alimentos

Rosângela Venâncio Nunes, Andesom Nunes de Sousa, Charles Washington Costa de Assis, Rita de Cassia Fonseca, Nayana de Almeida Adriano

Neste caso, a empresa não tem os dados da quilometragem (uma limitação para a análise); então será usado o peso da mercadoria, assim como no rateio da mão de obra, afinal o peso também influenciará no aumento dos custos. A Tabela 5 mostra o custo total e o valor que foi rateado para os clientes em análise, e a Tabela 6 apresenta o rateio proporcional a cada cliente.

Tabela 5: Total dos custos com transporte

\begin{tabular}{|c|c|c|}
\hline \multicolumn{3}{|c|}{ Despesas com Veículo } \\
\hline Manutenção de Veículo & & 337.716 \\
\hline Locação de Veículo & & 197.756 \\
\hline Combustíveis & & 670.109 \\
\hline TOTAL & $\mathbf{1 2 0 5 . 5 8 0}$ \\
\hline Peso Proporcional dos clientes da amostragem & $\mathbf{1 5 4 . 3 1 4 , 2 8}$ \\
\hline
\end{tabular}

Fonte: Dados da Pesquisa (2013). 
Contribuições das informações obtidas a partir da Análise Multidimensional de Custos - 0 caso de uma Distribuidora de Alimentos

Rosângela Venâncio Nunes, Andesom Nunes de Sousa, Charles Washington Costa de Assis, Rita de Cassia Fonseca, Nayana de Almeida Adriano

Tabela 6: Rateio dos custos com Transporte

\begin{tabular}{|c|c|c|c|}
\hline Cliente & Peso Kg & \multicolumn{1}{|c|}{ Peso } & Transporte \\
\hline Cliente A & 950.189 & $24,50 \%$ & $37.800,13$ \\
\hline Cliente B & 723.396 & $18,65 \%$ & $28.777,92$ \\
\hline Cliente C & 370.372 & $9,55 \%$ & $14.734,03$ \\
\hline Cliente D & 192.013 & $4,95 \%$ & $7.638,60$ \\
\hline Cliente E & 336.911 & $8,69 \%$ & $13.402,89$ \\
\hline Cliente F & 270.449 & $6,97 \%$ & $10.758,92$ \\
\hline Cliente G & 367.705 & $9,48 \%$ & $14.627,93$ \\
\hline Cliente H & 410.505 & $10,58 \%$ & $16.330,59$ \\
\hline Cliente I & 152.869 & $3,94 \%$ & $6.081,39$ \\
\hline Cliente J & 95.327 & $2,46 \%$ & $3.792,27$ \\
\hline Cliente K & 4.410 & $0,11 \%$ & 175,44 \\
\hline Cliente L & 257 & $0,01 \%$ & 10,22 \\
\hline Cliente M & 1190 & $0,03 \%$ & 47,34 \\
\hline Cliente N & 810 & $0,02 \%$ & 32,22 \\
\hline Cliente O & 701 & $0,02 \%$ & 27,89 \\
\hline Cliente P & 575 & $0,02 \%$ & 22,87 \\
\hline Cliente Q & 131 & $0,00 \%$ & 5,21 \\
\hline Cliente R & 1020 & $0,03 \%$ & 40,58 \\
\hline Cliente S & 62 & $0,00 \%$ & 2,47 \\
\hline Cliente T & 135 & $0,00 \%$ & 5,37 \\
\hline TOTAL & $\mathbf{3 . 8 7 9 . 0 2 7}$ & $\mathbf{1 2 , 8 0 \%}$ & $\mathbf{1 5 4 . 3 1 4 , 2 8}$ \\
\hline \multicolumn{2}{|c|}{} & \multicolumn{2}{|c}{} \\
\hline
\end{tabular}

Fonte: Dados da Pesquisa (2013).

\subsubsection{Resultado da Lucratividade por Cliente}

Neste estudo de caso, todos os custos incorridos por cada cliente foram apropriados pela ferramenta de Análise de Lucratividade por Cliente.

Dessa forma, os custos apropriados foram: mão de obra, na qual estão inseridos o motorista, os carregadores e descarregadores do caminhão, o faturista e a comissão dos representantes de 1,5\%, que ainda será apropriada. Foi usado o mesmo critério de rateio entre a mão de obra e o gasto com transporte, no caso, o peso da mercadoria. A Tabela 7 mostra os clientes da amostragem com custos alocados, o CMV e a Comissão dos representantes. 
Contribuições das informações obtidas a partir da Análise Multidimensional de Custos - 0 caso de uma Distribuidora de Alimentos

Rosângela Venâncio Nunes, Andesom Nunes de Sousa, Charles Washington Costa de Assis, Rita de Cassia Fonseca, Nayana de Almeida Adriano

Tabela 7: Custo Direto por Cliente

\begin{tabular}{|c|c|c|c|c|c|c|}
\hline & Clientes & $\begin{array}{c}\text { Mão de } \\
\text { Obra }\end{array}$ & $\begin{array}{c}\text { Gasto } \\
\text { com } \\
\text { Transporte }\end{array}$ & Mercadoria & $\begin{array}{c}\text { Comissão } \\
\mathbf{1 , 5 \% ~ s / ~} \\
\text { Venda }\end{array}$ & $\begin{array}{c}\text { Custo Direto } \\
\text { por Cliente }\end{array}$ \\
\hline 1 & Cliente A & $34.231,47$ & $37.800,13$ & $2.767 .853,64$ & $45.586,55$ & $2.885 .471,79$ \\
\hline 2 & Cliente B & $26.061,03$ & $28.777,92$ & $1.830 .123,67$ & $29.551,92$ & $1.914 .514,54$ \\
\hline 3 & Cliente C & $13.343,01$ & $14.734,03$ & $1.362 .710,03$ & $22.732,05$ & $1.413 .519,12$ \\
\hline 4 & Cliente D & $6.917,45$ & $7.638,60$ & $1.044 .611,05$ & $17.610,58$ & $1.076 .777,68$ \\
\hline 5 & Cliente E & $12.137,54$ & $13.402,89$ & $1.002 .373,06$ & $16.611,33$ & $1.044 .524,82$ \\
\hline 6 & Cliente F & $9.743,18$ & $10.758,92$ & $977.880,00$ & $16.120,35$ & $1.014 .502,45$ \\
\hline 7 & Cliente G & $13.246,92$ & $14.627,93$ & $957.880,56$ & $15.835,20$ & $1.001 .590,61$ \\
\hline 8 & Cliente H & $14.788,84$ & $16.330,59$ & $539.473,35$ & $15.205,06$ & $585.797,84$ \\
\hline 9 & Cliente I & $5.507,25$ & $6.081,39$ & $300.297,44$ & $3.667,10$ & $315.553,18$ \\
\hline 10 & Cliente J & $3.434,25$ & $3.792,27$ & $129.763,08$ & 180,84 & $137.170,44$ \\
\hline 11 & Cliente K & 158,87 & 175,44 & $9.698,46$ & 83,66 & $10.116,43$ \\
\hline 12 & Cliente L & 9,26 & 10,22 & $4.201,34$ & 66,75 & $4.287,57$ \\
\hline 13 & Cliente M & 42,87 & 47,34 & $3.501,65$ & 52,12 & $3.643,98$ \\
\hline 14 & Cliente N & 29,18 & 32,22 & $2.690,32$ & 47,19 & $2.798,91$ \\
\hline 15 & Cliente O & 25,25 & 27,89 & $2.403,67$ & 45,32 & $2.502,13$ \\
\hline 16 & Cliente P & 20,71 & 22,87 & $2.270,08$ & 19,95 & $2.333,61$ \\
\hline 17 & Cliente Q & 4,72 & 5,21 & $1.652,26$ & 19,80 & $1.681,99$ \\
\hline 18 & Cliente R & 36,75 & 40,58 & 982,58 & 10,85 & $1.070,76$ \\
\hline 19 & Cliente S & 2,23 & 2,47 & 927,16 & 10,85 & 942,71 \\
\hline 20 & Cliente T & 4,86 & 5,37 & $1.058,55$ & 10,17 & $1.078,95$ \\
\hline & TOTAL & $\mathbf{1 3 9 . 7 4 5 , 6 6}$ & $\mathbf{1 5 4 . 3 1 4 , 2 8}$ & $\mathbf{1 0 . 9 4 2 . 3 5 1 , 9 3}$ & $\mathbf{1 9 2 . 0 9 1 , 8 4}$ & $\mathbf{1 1 . 4 1 9 . 8 7 9 , 5 1}$ \\
\hline
\end{tabular}

Fonte: Dados da Pesquisa (2013).

Com a informação do Custo Direto por Cliente, chegou-se ao Lucro Direto por Cliente, inclusive percentual em relação a todos os clientes da empresa Alfa, como demonstrado na Tabela 8. 
Contribuições das informações obtidas a partir da Análise Multidimensional de Custos - 0 caso de uma Distribuidora de Alimentos

Rosângela Venâncio Nunes, Andesom Nunes de Sousa, Charles Washington Costa de Assis, Rita de Cassia Fonseca, Nayana de Almeida Adriano

Tabela 8: Lucro Direto por Cliente

\begin{tabular}{|c|c|c|c|c|c|}
\hline & Clientes & Receita & Custo Direto & $\begin{array}{l}\text { Lucro Direto } \\
\text { por Cliente }\end{array}$ & LDC \% \\
\hline 1 & Cliente A & $3.039 .103,30$ & $2.885 .471,79$ & $153.631,51$ & $5,32 \%$ \\
\hline 2 & Cliente B & $1.970 .128,13$ & $1.914 .514,54$ & $55.613,59$ & $2,90 \%$ \\
\hline 3 & Cliente C & $1.515 .469,82$ & $1.413 .519,12$ & $101.950,70$ & $7,21 \%$ \\
\hline 4 & Cliente D & $1.174 .038,36$ & $1.076 .777,68$ & $97.260,68$ & $9,03 \%$ \\
\hline 5 & Cliente E & $1.107 .421,76$ & $1.044 .524,82$ & $62.896,94$ & $6,02 \%$ \\
\hline 6 & Cliente F & $1.074 .690,12$ & $1.014 .502,45$ & $60.187,67$ & $5,93 \%$ \\
\hline 7 & Cliente G & $1.055 .680,16$ & $1.001 .590,61$ & $54.089,55$ & $5,40 \%$ \\
\hline 8 & Cliente $\mathrm{H}$ & $1.013 .670,42$ & $585.797,84$ & $427.872,58$ & $73,04 \%$ \\
\hline 9 & Cliente I & $575.670,18$ & $315.553,18$ & $260.117,00$ & $82,43 \%$ \\
\hline 10 & Cliente J & $244.473,63$ & $137.170,44$ & $107.303,19$ & $78,23 \%$ \\
\hline 11 & Cliente K & $12.056,16$ & $10.116,43$ & $1.939,73$ & $19,17 \%$ \\
\hline 12 & Cliente L & $5.577,28$ & $4.287,57$ & $1.289,71$ & $30,08 \%$ \\
\hline 13 & Cliente M & $4.449,90$ & $3.643,98$ & 805,92 & $22,12 \%$ \\
\hline 14 & Cliente N & $3.474,82$ & $2.798,91$ & 675,91 & $24,15 \%$ \\
\hline 15 & Cliente $\mathrm{O}$ & $3.146,16$ & $2.502,13$ & 644,03 & $25,74 \%$ \\
\hline 16 & Cliente P & $3.021,47$ & $2.333,61$ & 687,86 & $29,48 \%$ \\
\hline 17 & Cliente Q & $1.329,74$ & $1.681,99$ & 352,25 & $-20,94 \%$ \\
\hline 18 & Cliente R & $1.320,00$ & $1.070,76$ & 249,24 & $23,28 \%$ \\
\hline 19 & Cliente S & 723,00 & 942,71 & 219,71 & $-23,31 \%$ \\
\hline \multirow[t]{2}{*}{20} & Cliente T & 678,21 & $1.078,95$ & 400,74 & $-37,14 \%$ \\
\hline & TOTAL & $12.806 .123,62$ & $11.419 .879,51$ & $1.386 .243,11$ & $12,14 \%$ \\
\hline
\end{tabular}

Fonte: Dados da Pesquisa (2013).

O cliente é um objeto de análise muito relevante porque, por meio dele, a empresa pode classificar cada um de acordo com a rentabilidade que ele proporciona à empresa.

Muitas empresas estão buscando analisar a rentabilidade do relacionamento de grandes e até mesmo de pequenos clientes, em que a tecnologia da informação tem reduzido os custos de transação e de informação. Conhecer e classificar os clientes de acordo com a rentabilidade proporcionada à empresa faz lembrar a ação do princípio de Pareto, que classifica o cliente com base no grau de rentabilidade, maior ou menor, como, por exemplo, 20\% dos clientes podem estar proporcionando $80 \%$ da rentabilidade. (FARIA E COSTA, 2005. p. 338). 
Contribuições das informações obtidas a partir da Análise Multidimensional de Custos - 0 caso de uma Distribuidora de Alimentos

Rosângela Venâncio Nunes, Andesom Nunes de Sousa, Charles Washington Costa de Assis, Rita de Cassia Fonseca, Nayana de Almeida Adriano

Faria e Costa (2005) ainda dizem que, se o custo da prestação de serviço é baixo, mas a receita também, a empresa deve tentar aumentar as vendas para esses clientes. Se o custo de servir os clientes é alto e as vendas baixas, deve-se reavaliar se existe algum motivo estratégico para mantê-los.

Tomando como exemplo o cliente $\mathrm{J}$, com uma lucratividade direta de $78,23 \%$, conclui-se que este é o cliente com maior rentabilidade. Mesmo não tendo a receita mais significativa, os custos gerados para servi-lo, como transporte e mão-de-obra, são pequenos para sua receita. Pode-se então planejar alguma estratégia para aumentar as vendas para este cliente.

Outros clientes, como Q, S e T, deram prejuízo em suas operações de compra. Deve-se então reavaliar os motivos para continuar servindo-os.

Para estudar o padrão de rentabilidade dos clientes, Kaplan e Cooper (1998), citados por Faria e Costa (2005), sugerem a seguinte análise dos clientes no Quadro 2:

\begin{tabular}{|c|c|}
\hline CLIENTES DE ALTO CUSTO & CLIENTES DE BAIXO CUSTO \\
\hline Pedidos de produtos personalizados & Pedidos de produtos padrão \\
\hline Pedem quantidades pequenas & Pedem grandes quantidades \\
\hline Chegadas imprevisíveis de pedidos & Chegadas dos pedidos é previsível \\
\hline Entrega personalizada & Entrega padronizada \\
\hline Mudança das necessidades de entrega & Não mudam as condições das entregas \\
\hline Processamento manual & Processamento Eletrônico \\
\hline Grande volume de apoio prévio às vendas & Pouco ou nenhum apoio prévio às vendas \\
\hline (Recursos de marketing, técnicos e de vendas) & (Definição de preços e pedidos padrões) \\
\hline Exigem serviço pós-venda & Nenhum suporte pós-venda \\
\hline Exigem que a empresa mantenha suporte & Reposição proporcional à produção \\
\hline Pagam lentamente (contas a receber elevado) & Pagam no prazo \\
\hline
\end{tabular}

Quadro 2: Lucro Direto por Cliente

Fonte: Faria e Costa (2005, p. 342).

Conclui-se também, com esta análise, que o Resultado de Lucro gerado pelo sistema de informação da empresa não abrange os custos que neste trabalho foram 
Contribuições das informações obtidas a partir da Análise Multidimensional de Custos - 0 caso de uma Distribuidora de Alimentos

Rosângela Venâncio Nunes, Andesom Nunes de Sousa, Charles Washington Costa de Assis, Rita de

Cassia Fonseca, Nayana de Almeida Adriano

admitidos, assim a análise multidimensional por cliente fornece uma informação mais precisa do resultado deste objeto.

\subsection{Lucratividade Direta por Praça}

As praças são grupos de clientes divididos por região. Entende-se melhor quando é usado o exemplo de uma cidade e seus bairros. Cada bairro é uma região demarcada da cidade; assim funciona a divisão das praças. Toda a região atendida pela Alfa, como Fortaleza, região Metropolitana e o interior do Estado foram divididos por praças.

Decisões podem ser tomadas com o resultado desta análise, como, por exemplo, abertura de um novo centro de distribuição na região com maior demanda; praça com cliente em potencial pode receber uma estratégia de venda diferenciada para aumentar o número de clientes na região, dentre outras.

A empresa foi dividida em 324 praças, e a análise foi realizada em uma amostragem com 30 praças, como destaca a Tabela 9. São, em sua maioria, em cidades do interior do Estado. 
Contribuições das informações obtidas a partir da Análise Multidimensional de Custos - 0 caso de uma Distribuidora de Alimentos

Rosângela Venâncio Nunes, Andesom Nunes de Sousa, Charles Washington Costa de Assis, Rita de Cassia Fonseca, Nayana de Almeida Adriano

Tabela 9: Amostragem das Praças

\begin{tabular}{|c|c|c|c|c|c|}
\hline & Praça & $\begin{array}{c}\text { No de } \\
\text { Clientes }\end{array}$ & Peso Kg & Venda & $\begin{array}{c}\text { Lucro } \\
\text { Bruto } \\
\%\end{array}$ \\
\hline 1 & Praça A & 20,00 & 768.022 & $406394947,00 \%$ & 11,89 \\
\hline 2 & Praça B & 11,00 & 1.339 .304 & $388251101,00 \%$ & 8,42 \\
\hline 3 & Praça C & 22,00 & 960.776 & $302498522,00 \%$ & 8,89 \\
\hline 4 & Praça D & 16,00 & 723.752 & $281268137,00 \%$ & 10,79 \\
\hline 5 & Praça E & 19,00 & 857.082 & $267239661,00 \%$ & 9,18 \\
\hline 6 & Praça F & 11,00 & 808.337 & $260998928,00 \%$ & 8,73 \\
\hline 7 & Praça G & 95,00 & 665.157 & $255111261,00 \%$ & 10,45 \\
\hline 8 & Praça H & 151,00 & 507.136 & $183246295,00 \%$ & 8,49 \\
\hline 9 & Praça I & 110,00 & 516.746 & $173681037,00 \%$ & 11,18 \\
\hline 10 & Praça J & 4,00 & 557.514 & $165863288,00 \%$ & 8,04 \\
\hline 11 & Praça K & 87,00 & 528.011 & $145973754,00 \%$ & 9,64 \\
\hline 12 & Praça L & 78,00 & 346.764 & $144656024,00 \%$ & 11,96 \\
\hline 13 & Praça M & 118,00 & 331.221 & $143285527,00 \%$ & 11,58 \\
\hline 14 & Praça N & 64,00 & 334.253 & $140223570,00 \%$ & 12,18 \\
\hline 15 & Praça O & 90,00 & 330.479 & $139438178,00 \%$ & 7,83 \\
\hline 16 & Praça P & 67,00 & 290.019 & $122070259,00 \%$ & 10,15 \\
\hline 17 & Praça Q & 28,00 & 261.226 & $102548362,00 \%$ & 9,79 \\
\hline 18 & Praça R & 36,00 & 283.332 & $99168331,00 \%$ & 7,76 \\
\hline 19 & Praça S & 90,00 & 267.005 & $98132841,00 \%$ & 10,32 \\
\hline 20 & Praça T & 62,00 & 217.579 & $97183117,00 \%$ & 9,43 \\
\hline 21 & Praça U & 92,00 & 301.776 & $95176097,00 \%$ & 9,12 \\
\hline 22 & Praça V & 97,00 & 257.887 & $93668083,00 \%$ & 13,42 \\
\hline 23 & Praça W & 35,00 & 328.896 & $93422421,00 \%$ & 10,11 \\
\hline 24 & Praça X & 15,00 & 259.889 & $86008579,00 \%$ & 9,70 \\
\hline 25 & Praça Y & 57,00 & 198.526 & $82853473,00 \%$ & 12,34 \\
\hline 26 & Praça Z & 19,00 & 260.282 & $72576561,00 \%$ & 8,12 \\
\hline 27 & Praça AB & 33,00 & 245.074 & $71631657,00 \%$ & 10,81 \\
\hline 28 & Praça AC & 23,00 & 239.190 & $70406917,00 \%$ & 10,78 \\
\hline 29 & Praça AD & 23,00 & 173.678 & $63065683,00 \%$ & 8,89 \\
\hline 30 & Praça AE & 49,00 & 172.139 & $61818675,00 \%$ & 11,19 \\
\hline & TotaL & $\mathbf{1 . 6 2 2 , 0 0}$ & $\mathbf{1 3 . 3 3 1 . 0 5 2}$ & $\mathbf{7 . 0 7 8 . 6 1 2 , 8 6}$ & 9,95 \\
\hline & & & & & \\
\hline
\end{tabular}

Fonte: Dados da Pesquisa (2013).

O método de Lucratividade utilizado para descobrir os custos das praças foi o mesmo utilizado nos clientes, assim como o rateio dos custos indiretos. $\mathrm{Na}$ análise anterior, a mão de obra diretamente ligada aos clientes foi rateada entre eles, assim como foi feito entre as praças, que abrande um grupo de clientes. Os custos com 
Contribuições das informações obtidas a partir da Análise Multidimensional de Custos - 0 caso de uma Distribuidora de Alimentos

Rosângela Venâncio Nunes, Andesom Nunes de Sousa, Charles Washington Costa de Assis, Rita de Cassia Fonseca, Nayana de Almeida Adriano

transporte também foram rateados entre as praças, usando-se o mesmo objeto de rateio, como será explicado nos próximos tópicos.

\subsubsection{Mão de Obra}

A mão de obra foi a mesma usada na análise anterior; a diferença é que será rateada em outra proporção. O objeto de rateio mais adequado seria a quantidade de viagens realizadas para cada praça, porque, sempre que acontece uma entrega, a mão de obra é usada, mas como a empresa não tem essa informação disponível, foi usado o peso das mercadorias que, quanto maior, mais necessidade há de mão de obra.

O custo com esta atividade foi de $R \$ 1.091 .763,00$, como demonstrado na análise dos clientes (Tabela 3). O peso das mercadorias entregues para as praças desta amostragem corresponde a 43,99\% do total de toda a mercadoria entregue pela Alfa (13.331.052 kg / 30.303.538), proporcionando um custo com mão de obra de $R \$$ 480.266,54. Esse custo foi rateado pelas praças proporcionalmente com seu peso e é apresentado na Tabela 10. 
Contribuições das informações obtidas a partir da Análise Multidimensional de Custos - 0 caso de uma Distribuidora de Alimentos

Rosângela Venâncio Nunes, Andesom Nunes de Sousa, Charles Washington Costa de Assis, Rita de Cassia Fonseca, Nayana de Almeida Adriano

Tabela 10: Rateio da Mão-de-Obra às Praças

\begin{tabular}{|c|c|c|c|c|c|}
\hline & Praça & $\begin{array}{c}\text { No de } \\
\text { Clientes }\end{array}$ & Peso Kg & Peso \% & Mão-de-Obra \\
\hline 1 & Praça A & 20 & 768.022 & 5,76 & $27.668,88$ \\
\hline 2 & Praça B & 11 & 1.339 .304 & 10,05 & $48.249,97$ \\
\hline 3 & Praça C & 22 & 960.776 & 7,21 & $34.613,06$ \\
\hline 4 & Praça D & 16 & 723.752 & 5,43 & $26.074,00$ \\
\hline 5 & Praça E & 19 & 857.082 & 6,43 & $30.877,37$ \\
\hline 6 & Praça F & 11 & 808.337 & 6,06 & $29.121,27$ \\
\hline 7 & Praça G & 95 & 665.157 & 4,99 & $23.963,05$ \\
\hline 8 & Praça H & 151 & 507.136 & 3,80 & $18.270,16$ \\
\hline 9 & Praça I & 110 & 516.746 & 3,88 & $18.616,37$ \\
\hline 10 & Praça J & 4 & 557.514 & 4,18 & $20.085,09$ \\
\hline 11 & Praça K & 87 & 528.011 & 3,96 & $19.022,21$ \\
\hline 12 & Praça L & 78 & 346.764 & 2,60 & $12.492,57$ \\
\hline 13 & Praça M & 118 & 331.221 & 2,48 & $11.932,62$ \\
\hline 14 & Praça N & 64 & 334.253 & 2,51 & $12.041,85$ \\
\hline 15 & Praça O & 90 & 330.479 & 2,48 & $1.905,89$ \\
\hline 16 & Praça P & 67 & 290.019 & 2,18 & $10.448,27$ \\
\hline 17 & Praça Q & 28 & 261.226 & 1,96 & $9.410,97$ \\
\hline 18 & Praça R & 36 & 283.332 & 2,13 & $10.207,36$ \\
\hline 19 & Praça S & 90 & 267.005 & 2,00 & $9.619,16$ \\
\hline 20 & Praça T & 62 & 217.579 & 1,63 & $7.838,53$ \\
\hline 21 & Praça U & 92 & 301.776 & 2,26 & $10.871,83$ \\
\hline 22 & Praça V & 97 & 257.887 & 1,93 & $9.290,68$ \\
\hline 23 & Praça W & 35 & 328.896 & 2,47 & $11.848,86$ \\
\hline 24 & Praça X & 15 & 259.889 & 1,95 & $9.362,80$ \\
\hline 25 & Praça Y & 57 & 198.526 & 1,49 & $7.152,13$ \\
\hline 26 & Praça Z & 19 & 260.282 & 1,95 & $9.376,96$ \\
\hline 27 & Praça AB & 33 & 245.074 & 1,84 & $8.829,07$ \\
\hline 28 & Praça AC & 23 & 239.190 & 1,79 & $8.617,10$ \\
\hline 29 & Praça AD & 23 & 173.678 & 1,30 & $6.256,95$ \\
\hline 30 & Praça AE & 49 & 172.139 & 1,29 & $6.201,51$ \\
\hline & TOTAL & $\mathbf{1 . 6 2 2}$ & $\mathbf{1 3 . 3 3 1 . 0 5 2}$ & $\mathbf{1 0 0 , 0 0}$ & $\mathbf{4 8 0 . 2 6 6 , 5 4}$ \\
\hline & & & & & \\
\hline
\end{tabular}

Fonte: Dados da Pesquisa (2013).

\subsubsection{Transporte}

Os custos com transporte foram usados para analisar os clientes, assim como serão usados nas praças. O objeto de rateio mais adequado seriam os quilômetros rodados, mas, como a empresa não tem a informação disponível, será rateado pelo 
Contribuições das informações obtidas a partir da Análise Multidimensional de Custos - 0 caso de uma Distribuidora de Alimentos

Rosângela Venâncio Nunes, Andesom Nunes de Sousa, Charles Washington Costa de Assis, Rita de Cassia Fonseca, Nayana de Almeida Adriano

mesmo objeto usado no rateio de transporte dos clientes: o peso da mercadoria, conforme a Tabela 11.

Tabela 11: Despesas com Veículos rateado na amostra

\begin{tabular}{|c|c|c|}
\hline \multicolumn{3}{|c|}{ Despesas com Veículos rateadas na amostra } \\
\hline Manutenção de Veículo & & $337.715,67$ \\
\hline Locação de Veículo & & $197.755,62$ \\
\hline Combustíveis & & $670.109,00$ \\
\hline TOTAL & & $1.205 .580,29$ \\
\hline Peso Proporcional das praças da amostragem & $43,99 \%$ & $530.334,77$ \\
\hline
\end{tabular}

Fonte: Dados da Pesquisa (2013).

O valor de $530.334,77$ foi rateado proporcionalmente às praças pelo peso da mercadoria entregue em cada uma e obteve o resultado a seguir representado na Tabela 12: 
Contribuições das informações obtidas a partir da Análise Multidimensional de Custos - 0 caso de uma Distribuidora de Alimentos

Rosângela Venâncio Nunes, Andesom Nunes de Sousa, Charles Washington Costa de Assis, Rita de Cassia Fonseca, Nayana de Almeida Adriano

Tabela 12: Rateio do Transporte às Praças

\begin{tabular}{|c|c|c|c|c|c|}
\hline & Praça & $\begin{array}{c}\text { No de } \\
\text { Clientes }\end{array}$ & Peso Kg & Peso \% & Transporte \\
\hline 1 & Praça A & 20 & 768.022 & 5,76 & $30.553,39$ \\
\hline 2 & Praça B & 11 & 1.339 .304 & 10,05 & $53.280,08$ \\
\hline 3 & Praça C & 22 & 960.776 & 7,21 & $38.221,51$ \\
\hline 4 & Praça D & 16 & 723.752 & 5,43 & $28.792,24$ \\
\hline 5 & Praça E & 19 & 857.082 & 6,43 & $34.096,36$ \\
\hline 6 & Praça F & 11 & 808.337 & 6,06 & $32.157,19$ \\
\hline 7 & Praça G & 95 & 665.157 & 4,99 & $26.461,22$ \\
\hline 8 & Praça H & 151 & 507.136 & 3,80 & $20.174,84$ \\
\hline 9 & Praça I & 110 & 516.746 & 3,88 & $20.557,15$ \\
\hline 10 & Praça J & 4 & 557.514 & 4,18 & $22.178,97$ \\
\hline 11 & Praça K & 87 & 528.011 & 3,96 & $21.005,29$ \\
\hline 12 & Praça L & 78 & 346.764 & 2,60 & $13.794,94$ \\
\hline 13 & Praça M & 118 & 331.221 & 2,48 & $13.176,61$ \\
\hline 14 & Praça N & 64 & 334.253 & 2,51 & $13.297,22$ \\
\hline 15 & Praça O & 90 & 330.479 & 2,48 & $13.147,09$ \\
\hline 16 & Praça P & 67 & 290.019 & 2,18 & $11.537,51$ \\
\hline 17 & Praça Q & 28 & 261.226 & 1,96 & $10.392,07$ \\
\hline 18 & Praça R & 36 & 283.332 & 2,13 & $11.271,49$ \\
\hline 19 & Praça S & 90 & 267.005 & 2,00 & $10.621,97$ \\
\hline 20 & Praça T & 62 & 217.579 & 1,63 & $8.655,71$ \\
\hline 21 & Praça U & 92 & 301.776 & 2,26 & $12.005,23$ \\
\hline 22 & Praça V & 97 & 257.887 & 1,93 & $10.259,24$ \\
\hline 23 & Praça W & 35 & 328.896 & 2,47 & $13.084,11$ \\
\hline 24 & Praça X & 15 & 259.889 & 1,95 & $10.338,88$ \\
\hline 25 & Praça Y & 57 & 198.526 & 1,49 & $7.897,74$ \\
\hline 26 & Praça Z & 19 & 260.282 & 1,95 & $10.354,52$ \\
\hline 27 & Praça AB & 33 & 245.074 & 1,84 & $9.749,51$ \\
\hline 28 & Praça AC & 23 & 239.190 & 1,79 & $9.515,44$ \\
\hline 29 & Praça AD & 23 & 173.678 & 1,30 & $6.909,24$ \\
\hline 30 & Praça AE & 49 & 172.139 & 1,29 & $6.848,02$ \\
\hline & TOTAL & 1.622 & 13.331 .052 & 100,00 & $530.334,77$ \\
\hline & & & & & \\
\hline
\end{tabular}

Fonte: Dados da Pesquisa (2013).

\subsubsection{Resultado do Custeio por Praça}

$\mathrm{Na}$ análise por praça, assim como por cliente, foi usada a ferramenta de Análise de Lucratividade por Cliente/Praça, no qual os custos incorridos em cada praça foram 
Contribuições das informações obtidas a partir da Análise Multidimensional de Custos - 0 caso de uma Distribuidora de Alimentos

Rosângela Venâncio Nunes, Andesom Nunes de Sousa, Charles Washington Costa de Assis, Rita de Cassia Fonseca, Nayana de Almeida Adriano

rateados entre elas. O Objeto de rateio mais apropriado para mão de obra seria 0 número de viagens, levando-se em consideração que a empresa não tem a informação de quantas viagens foram realizadas para cada praça. Foi usado o peso das mercadorias, assim como na atividade de transporte dos clientes, por não haver os dados dos quilômetros rodados, acabando-se por utilizar esse objeto de rateio.

O valor da mercadoria foi tirado do relatório gerencial fornecido pela organização. Na Tabela 13, podem ser verificadas as praças da amostragem com os custos alocados, o CMV e a comissão dos representantes.

Tabela 13: Custeio Direto por Praça

\begin{tabular}{|c|c|c|c|c|c|c|}
\hline & Praças & $\begin{array}{l}\text { Mão de } \\
\text { Obra }\end{array}$ & Transporte & Mercadoria & $\begin{array}{c}\text { Comissão } \\
1,5 \% \text { s/ Venda }\end{array}$ & $\begin{array}{l}\text { Custo Direto } \\
\text { por Praça }\end{array}$ \\
\hline 1 & Praça A & $27.668,88$ & $30.553,39$ & $3.632 .093,55$ & $60.959,24$ & $3.751 .275,06$ \\
\hline 2 & Praça B & $8.249,97$ & $53.280,08$ & $3.580 .991,52$ & $58.237,67$ & $3.740 .759,24$ \\
\hline 3 & Praça C & $34.613,06$ & $38.221,51$ & $.778 .019,30$ & $45.374,78$ & $2.896 .228,65$ \\
\hline 4 & Praça D & $26.074,00$ & $28.792,24$ & $2.538 .750,22$ & $42.190,22$ & $2.635 .806,68$ \\
\hline 5 & Praça E & $30.877,37$ & $34.096,36$ & 94 & 5,95 & 7,62 \\
\hline 6 & Praça F & $29.121,27$ & 7,19 & & 9,84 &, 91 \\
\hline 7 & $\mathrm{G}$ & $23.963,05$ & 1,22 & & 6,69 & 5,29 \\
\hline 8 & Praça H & $18.270,16$ & $20.174,84$ & $1.689 .061,62$ & $27.486,94$ & $1.754 .993,57$ \\
\hline 9 & Praça I & $18.616,37$ & $20.557,15$ & $1.562 .160,79$ & $26.052,16$ & $1.627 .386,46$ \\
\hline 10 & & 20.0 & 22. & & 49 & 14 \\
\hline 11 & Praça K & $19.022,21$ & 21.0 & 41 & 6,06 & 4,97 \\
\hline 12 & Praça L & $12.492,57$ & $13.794,94$ & $1.292 .033,08$ & $21.698,40$ & $1.340 .018,99$ \\
\hline 13 & Praça M & 11.93 & 13. & 63 & 2,83 & $0.752,68$ \\
\hline 14 & $\mathrm{aN}$ & 12.0 & 22 & 25 & 3,54 & 9,86 \\
\hline 15 & Praça O & $1.905,89$ & $13.147,09$ & $1.293 .129,72$ & 5,73 & $1.339 .098,42$ \\
\hline 16 & Praça P & $10.448,27$ & 7,51 & 8,42 & 0,54 & $1.148 .514,74$ \\
\hline 17 & Praça Q & 9.4 & 07 & & 2,25 & 226,30 \\
\hline 18 & Praça R & 10.2 & 49 & 33 & 5,25 & 24,43 \\
\hline 19 & Praça S & 9.61 & 1,97 & & 9,93 & 90,08 \\
\hline 20 & Praça T & $7.838,53$ & 71 & 4,78 & $14.577,47$ & $919.156,49$ \\
\hline 21 & Praça U & $10.871,83$ & $12.005,23$ & $872.214,97$ & $14.276,41$ & $909.368,44$ \\
\hline 22 & Praça V & $9.290,68$ & $10.259,24$ & & $14.050,21$ & $859.451,68$ \\
\hline 23 & Praça W & 11.8 & & &, 36 & 92,62 \\
\hline 24 & Praça X & $9.362,80$ & $10.338,88$ & $784.034,45$ & $12.901,29$ & $816.637,42$ \\
\hline 25 & Praça Y & $7.152,13$ & $7.897,74$ & $737.524,24$ & $12.428,02$ & $765.002,13$ \\
\hline 26 & Praça Z & 9.37 & 10.3 & & $10.886,48$ & $701.877,31$ \\
\hline 27 & Praça AB & $8.829,07$ & $9.749,51$ & $646.436,76$ & $10.744,75$ & $675.760,10$ \\
\hline 28 & Praça AC & $8.617,10$ & $9.515,44$ & $635.556,21$ & $10.561,04$ & $664.249,78$ \\
\hline
\end{tabular}


Contribuições das informações obtidas a partir da Análise Multidimensional de Custos - 0 caso de uma Distribuidora de Alimentos

Rosângela Venâncio Nunes, Andesom Nunes de Sousa, Charles Washington Costa de Assis, Rita de Cassia Fonseca, Nayana de Almeida Adriano

\begin{tabular}{|c|c|c|c|c|c|c|}
\hline 29 & Praça AD & $6.256,95$ & $6.909,24$ & $579.168,73$ & $9.459,85$ & $601.794,78$ \\
\hline 30 & Praça AE & $6.201,51$ & $6.848,02$ & $555.973,33$ & $9.272,80$ & $578.295,66$ \\
\hline \multicolumn{2}{|c|}{ TOTAL } & $\mathbf{4 8 0 . 2 6 6 , 5 4}$ & $\mathbf{5 3 0 . 3 3 4 , 7 7}$ & $\mathbf{4 2 . 8 2 1 . 4 5 4 , 9 9}$ & $\mathbf{7 0 6 . 1 7 9 , 1 9}$ & $\mathbf{4 4 . 5 3 8 . 2 3 5 , 4 9}$ \\
\hline
\end{tabular}

Fonte: Dados da Pesquisa (2013).

Com a informação do Custo Direto por Região, obteve-se, na Tabela 14, o Lucro Direto por Praça, inclusive seu percentual em relação a todas as praças.

Tabela 14: Custeio Direto por Praça

\begin{tabular}{|c|c|c|c|c|c|c|}
\hline & Clientes & $\begin{array}{c}\text { No de } \\
\text { Clientes }\end{array}$ & Receita & $\begin{array}{c}\text { Custo Direto } \\
\text { por Praça }\end{array}$ & $\begin{array}{c}\text { Lucro Direto } \\
\text { por Praça }\end{array}$ & LDC \% \\
\hline 1 & Praça A & 20 & $4.063 .949,47$ & $3.751 .275,06$ & $312.674,41$ & $8,34 \%$ \\
\hline 2 & Praça B & 11 & $3.882 .511,01$ & $3.740 .759,24$ & $141.751,77$ & $3,79 \%$ \\
\hline 3 & Praça C & 22 & $3.024 .985,22$ & $2.896 .228,65$ & $128.756,57$ & $4,45 \%$ \\
\hline 4 & Praça D & 16 & $2.812 .681,37$ & $2.635 .806,68$ & $176.874,69$ & $6,71 \%$ \\
\hline 5 & Praça E & 19 & $2.672 .396,61$ & $2.552 .757,62$ & $119.638,99$ & $4,69 \%$ \\
\hline 6 & Praça F & 11 & $2.609 .989,28$ & $2.500 .859,91$ & $109.129,37$ & $4,36 \%$ \\
\hline 7 & Praça G & 95 & $2.551 .112,61$ & $2.398 .435,29$ & $152.677,32$ & $6,37 \%$ \\
\hline 8 & Praça H & 151 & $1.832 .462,95$ & $1.754 .993,57$ & $77.469,38$ & $4,41 \%$ \\
\hline 9 & Praça I & 110 & $1.736 .810,37$ & $1.627 .386,46$ & $109.423,91$ & $6,72 \%$ \\
\hline 10 & Praça J & 4 & $1.658 .632,88$ & $1.602 .346,14$ & $56.286,74$ & $3,51 \%$ \\
\hline 11 & Praça K & 87 & $1.459 .737,54$ & $1.393 .314,97$ & $66.422,57$ & $4,77 \%$ \\
\hline 12 & Praça L & 78 & $1.446 .560,24$ & $1.340 .018,99$ & $106.541,25$ & $7,95 \%$ \\
\hline 13 & Praça M & 118 & $1.432 .855,27$ & $1.330 .752,68$ & $102.102,59$ & $7,67 \%$ \\
\hline 14 & Praça N & 64 & $1.402 .235,70$ & $1.296 .359,86$ & $105.875,84$ & $8,17 \%$ \\
\hline 15 & Praça O & 90 & $1.394 .381,78$ & $1.339 .098,42$ & $55.283,36$ & $4,13 \%$ \\
\hline 16 & Praça P & 67 & $1.220 .702,59$ & $1.148 .514,74$ & $72.187,85$ & $6,29 \%$ \\
\hline 17 & Praça Q & 28 & $1.025 .483,62$ & $969.226,30$ & $56.257,32$ & $5,80 \%$ \\
\hline 18 & Praça R & 36 & $991.683,31$ & $956.624,43$ & $35.058,88$ & $3,66 \%$ \\
\hline 19 & Praça S & 90 & $981.328,41$ & $924.490,08$ & $56.838,33$ & $6,15 \%$ \\
\hline 20 & Praça T & 62 & $971.831,17$ & $919.156,49$ & $52.674,68$ & $5,73 \%$ \\
\hline 21 & Praça U & 92 & $951.760,97$ & $909.368,44$ & $42.392,53$ & $4,66 \%$ \\
\hline 22 & Praça V & 97 & $936.680,83$ & $859.451,68$ & $77.229,15$ & $8,99 \%$ \\
\hline 23 & Praça W & 35 & $934.224,21$ & $887.392,62$ & $46.831,59$ & $5,28 \%$ \\
\hline 24 & Praça X & 15 & $860.085,79$ & $816.637,42$ & $43.448,37$ & $5,32 \%$ \\
\hline 25 & Praça Y & 57 & $828.534,73$ & $765.002,13$ & $63.532,60$ & $8,30 \%$ \\
\hline 26 & Praça Z & 19 & $725.765,61$ & $701.877,31$ & $23.888,30$ & $3,40 \%$ \\
\hline 27 & Praça AB & 33 & $716.316,57$ & $675.760,10$ & $40.556,47$ & $6,00 \%$ \\
\hline 28 & Praça AC & 23 & $704.069,17$ & $664.249,78$ & $39.819,39$ & $5,99 \%$ \\
\hline & & & & & & \\
\hline
\end{tabular}


Contribuições das informações obtidas a partir da Análise Multidimensional de Custos - 0 caso de uma Distribuidora de Alimentos Rosângela Venâncio Nunes, Andesom Nunes de Sousa, Charles Washington Costa de Assis, Rita de Cassia Fonseca, Nayana de Almeida Adriano

\begin{tabular}{|c|l|c|c|c|c|c|}
\hline 29 & Praça AD & 23 & $630.656,83$ & $601.794,78$ & $28.862,05$ & $4,80 \%$ \\
\hline \multirow{2}{*}{30} & Praça AE & 49 & $618.186,75$ & $578.295,66$ & $39.891,09$ & $6,90 \%$ \\
\hline \multirow{2}{*}{ TOTAL } & $\mathbf{1 . 6 2 2}$ & $\mathbf{4 7 . 0 7 8 . 6 1 2 , 8 6}$ & $\mathbf{4 4 . 5 3 8 . 2 3 5 , 4 9}$ & $\mathbf{2 . 5 4 0 . 3 7 7 , 3 7}$ & $\mathbf{5 , 7 0 \%}$ \\
\hline
\end{tabular}

Fonte: Dados da Pesquisa (2013).

Conclui-se, nesta análise, que, assim como com os clientes, o resultado de lucro gerado pelo sistema de informação não abrange os custos que neste trabalho foram admitidos; assim, a análise por praça fornece uma informação mais precisa do resultado deste objeto.

Em relação à praça $A$, por exemplo, no relatório gerencial da empresa, seu lucro era de 11,89\%; após a apropriação dos custos ligados diretamente às praças, o mesmo passou a ser de $8,34 \%$. Esse percentual de lucro corresponde a um número de vinte clientes, que, ao compará-lo com a praça H (151 clientes e LDC de 4,41\%), observa-se que o primeiro é quase duas vezes mais rentável. A partir desta informação, podem-se tomar decisões estratégicas para a organização.

A praça $\mathrm{J}$ obteve o menor resultado entre elas, com 3,51\% de Lucro Direto; é necessário estabelecer alguma política para aumentar seu resultado.

Observa-se assim a importância da gestão dos custos logísticos e a contribuição dada por esta análise.

\section{CONSIDERAÇÕES FINAIS}

A gestão de custos tem como objetivo instalar políticas nas organizações, para uma redução de custos e, simultaneamente, uma melhora na qualidade do serviço. Sem uma boa gestão, a empresa tende a perder-se entre seus objetivos e a forma como estes são colocados em prática, afirmação está embasada na explanação de alguns autores descritos neste trabalho.

Com o objetivo de identificar quais as contribuições que a análise multidimensional de custos logísticos pode oferecer à distribuidora, no sentido de atingir 
Contribuições das informações obtidas a partir da Análise Multidimensional de Custos - 0 caso de uma Distribuidora de Alimentos

Rosângela Venâncio Nunes, Andesom Nunes de Sousa, Charles Washington Costa de Assis, Rita de Cassia Fonseca, Nayana de Almeida Adriano

uma gestão eficiente, desenvolveu-se um estudo de caso utilizando-se como ferramenta a Lucratividade Direta por Cliente e por Região (praça). Foi constatado que o sistema gerencial e contábil não é capaz de fornecer a real rentabilidade de cada Cliente e Região. Com esta metodologia de análise, juntamente com as ferramentas já citadas, foi possível o alcance do objetivo mencionado.

Para tanto, primeiramente foi constatado quais os custos deveriam ser apropriados para a Lucratividade Direta por Cliente/Região. Além da mercadoria, foram rateados aos objetos de análise, proporcionalmente ao peso da mercadoria entregue a cada cliente ou praça, a mão de obra, a manutenção, o aluguel do veículo e o combustível.

As análises tiveram resultado satisfatório. Em relação aos clientes, pode-se afirmar qual deles teve a maior rentabilidade, assim como constatamos clientes com resultado negativo. A partir dessas informações, podem-se tomar decisões estratégicas como impulsionar as vendas para aqueles clientes que possuem um custeio baixo e analisar se é válido manter, em sua carteira de clientes, aqueles que possuem resultado negativo. Tratando-se das regiões (praças), pode-se fazer a mesma análise feita pelo objeto cliente, ressaltando a simplicidade pelo fato da empresa ter apenas um centro de distribuição.

Foram encontradas ainda, nesta pesquisa, algumas limitações de informações como a quantidade de viagens feitas pelo caminhão da empresa aos clientes e as regiões. Essa informação era importante para que o rateio dos custos com mão de obra fosse o mais justo possível.

Quanto aos gastos com transporte (despesa com veículo, aluguel de veículos e combustível), também foi encontrado dificuldade porque o objeto de rateio mais fiel seria o quilômetro rodado. $\mathrm{Na}$ falta deste, foi utilizado como objeto de rateio, tanto para a mão de obra quanto para o transporte, o peso da mercadoria transportada.

A partir desta pesquisa, a distribuidora poderá continuar a fazer a Análise Multidimensional para um maior controle dos custos agregados aos clientes e Regiões. 
Contribuições das informações obtidas a partir da Análise Multidimensional de Custos - 0 caso de uma Distribuidora de Alimentos

Rosângela Venâncio Nunes, Andesom Nunes de Sousa, Charles Washington Costa de Assis, Rita de Cassia Fonseca, Nayana de Almeida Adriano

Poderá tomar decisões mais fundamentadas e seguras em relação aos custos e lucros, isso na intenção de manter a empresa competitiva no mercado.

\section{REFERÊNCIAS}

ALMEIDA, M. de S. (2011). Elaboração de Projeto, TCC, Dissertação e Tese. São Paulo: Atlas.

BOWERSOX, D. J.; CLOSS, D. J. (2010). Logística empresarial. SP: Atlas.

DUARTE, H. M. (2012). Vantagens e dificuldades da integração com fornecedores de grãos: um estudo de caso em uma empresa no seguimento de avicultura. (2012). (Dissertação de Mestrado). Programa de Pós-Graduação em Administração, Faculdade Integrada de São Pedro, Minas Gerais.

FLEURY, P.F.; WANKE, P.F. (2000). Logística empresarial. São Paulo: Atlas.

FARIA, A. C.; COSTA, Maria de F. G. da. (2005). Gestão de custos logísticos. São Paulo: Atlas.

FERREIRA, J. A. S. (2007). Contabilidade de custos. São Paulo: Pearson.

HANSEN, D. R.; MOWEN, M. M. (2000). Gestão de custos, contabilidade e controle. Thomson Learning.

HORNGREN, C. T.; FOSTER, G.; DATAR, S. M. (1997). Contabilidade de custos. (9. ed.). LTC.

. (2004). Ed. São Paulo: Pearson.

KRIESES, P. (2009). A diferença entre eficiência e eficácia. Disponível em: $<$ www.baguete.com.br/colunas/paulo-krieser/29/01/2009/a-diferenca-entre-eficiencia-eeficacia>. Acesso em: 23/out/2014.

LUCCATTO, Rodrigo. Afinal, o que é gestão? Disponível em: $<$ www.administradores.com.br/noticias/negocios/afinal-o-que-e-gestao/48847/>. Acesso em: 23/out/2014.

MARTINS, E. (2003). Contabilidade de custos. (9. ed). São Paulo: Atlas, 2003. 
Contribuições das informações obtidas a partir da Análise Multidimensional de Custos - 0 caso de uma Distribuidora de Alimentos

Rosângela Venâncio Nunes, Andesom Nunes de Sousa, Charles Washington Costa de Assis, Rita de Cassia Fonseca, Nayana de Almeida Adriano

NOGUEIRA, Juliano Henriques. Custos logísticos $l$. Disponível em: $<w w w . t e c h o j e . c o m . b r / s i t e / t e c h o j e / c a t e g o r i a / d e t a l h e \_a r t i g o / 285>$. Acesso em: 23/out/ 2014.

SAMPIERI R. H.; COLLADO, C. F.; LUCIO, P. B. (2006). Metodologia de Pesquisa. (3. ed.). São Paulo: Mc Graw Hill.

SILVA JÚNIOR, J. B.; (Coord.). (2000). Custos, ferramenta de gestão. São Paulo: Atlas.

WERNKE, R. (2004). Gestão de custos, uma abordagem prática. São Paulo: Atlas.

Data de Submissão: 27/01/2016

Data de Aceite: 18/05/2016 